\title{
Students with Learning Disabilities and Challenging Behaviors in Jordan
}

\author{
Bashir Abu-Hamour ${ }^{1}$ \\ ${ }^{1}$ Faculty of Educational Sciences, Department of Counseling and Special Education, Mutah University, Jordan \\ Correspondence: Bashir Abu-Hamour, Faculty of Educational Sciences, Department of Counseling and Special \\ Education, Mutah University, Po. Box 6, 61710 Al-Karak, Jordan. Tel: 96-277-538-8547. E-mail: \\ dr.abuhamourwj@gmail.com
}

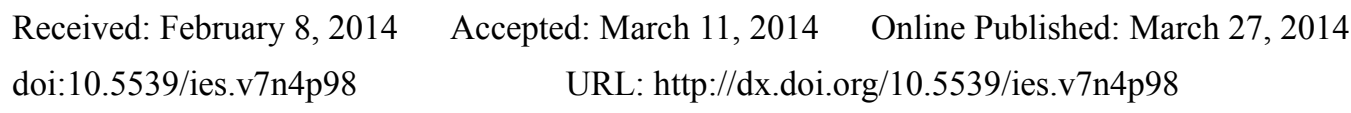

\begin{abstract}
This paper reports the findings of a study which aimed to explore the learning and behavioral characteristics of students with Learning Disabilities (LDs) in Jordan. Specifically, variables that related to challenging behaviors, school's type, and gender differences were investigated. Four resource room teachers in public and private schools were asked to rate (168) students with LDs on the Arabic version of the Building Blocks Questionnaire (Mather \& Goldstein, 2008). The findings indicate that over half of the students with LDs are suffering from challenging behaviors. In addition, students with LDs in private schools presented a better learning and behavioral profile than students with LDs in public schools. The results also showed that there are female under representation in special education services in Jordan. Implications and limitations of the study are discussed with reference to previous research and directions for future investigation.
\end{abstract}

Keywords: learning disabilities, challenging behaviors, special education, Jordan, schools, gender

\section{Introduction}

Learning disabilities are the most common type of disability in the field of special education. Currently, more students are identified as having specific learning disability than any other type of disability. Approximately, students with Learning disabilities account for half of all students receiving special education services in schools (Denton, Vaughn, \& Fletcher, 2003). A learning disability is thought to be a neurological disorder that affects the brain's ability to receive, process, store, and respond to information (National Research Center for Learning Disabilities, 2007). The term "learning disability" is used to explain difficulty a person of at least average intelligence has in acquiring basic academic and functional skills. Learning disabilities can affect a person's ability to understand or use spoken or written language, do mathematical calculations, coordinate movements, or direct attention.

For most children with learning disabilities (LDs), reading is the primary area of difficulty. People with reading disabilities often have difficulties with spelling and decoding skills, usually rooted in a phonological processing deficit. They may also have problems recognizing words that they have already learned (Ehri \& McCormick, 1998). Other symptoms of reading disability may include difficulties with comprehending text (Gersten, Fuchs, Williams, \& Baker, 2001). Other language-related learning disabilities include problems that interfere with oral and written communication, including speaking, listening, reading, spelling, and writing. Learning disabilities related to writing may be called dysgraphia, which generally refers to difficulty in handwriting, such as forming letters or words or writing within a defined space. Other learning disabilities related to writing include difficulties with spelling, semantic memory, morphological awareness, grammatical structures, organizing information, putting thoughts on paper, or working memory (Berninger, 2009). Learning disabilities related to math are sometimes called dyscalculia (Shaley, Manor, \& Gross-Tsur, 2005). Individuals with dyscalculia typically have difficulty understanding mathematical concepts and computation, sometimes even simple math problems. Math disabilities can include difficulties with spatial orientation, sequencing, and abstract concepts such as time and direction. In some individuals, a math disability may be linked to a concomitant reading disability, but in others math disabilities are more closely related to problems of working memory and problem solving (Swanson, 2009). The learning disabilities criteria for The Individuals with Disabilities Education Act (IDEA) identify disability categories that converge on academic and language difficulties. These categories 
include oral expression, listening comprehension, written expression, basic reading skills, reading comprehension, mathematics calculation, and mathematics reading (United States Department of Education, 2004). Further characteristics developed by current research include metacognitive deficits, social skills deficits, attention disorders, memory problems, and motor problems, among others (Mather \& Goldstein, 2008).

In terms of the gender differences among students with LDs, boys are generally more likely than girls to be identified for special education services. Learning disabilities are identified from 2 to 6 times more often among boys than girls (Smith, 1994). Furthermore, Vogel (1990) found that girls with LDs have more severe academic achievement deficits than boys in selected aspects of math and reading, whereas boys have more difficulty than girls in visual-motor abilities, spelling, and mechanics in written language. However, regardless of the gender, most of the students with LDs are suffering from challenging behaviors.

\subsection{Challenging Behaviors}

High rates of comorbidity between learning disabilities and challenging behaviors have led researchers to focus on behavioral problems when considering students with LDs (Forness \& Kavale, 2001; Mather \& Goldstein, 2008). Chamberlain, Cheung-Chung, and Jenner (1993) estimated that between $30 \%$ and 50\% of students with LDs exhibited varying degrees of challenging behaviors. Similar findings were documented by Male (1996) in a national survey of maintained schools for children and young people with severe LDs in England. The researcher found that $80 \%$ of schools that serve students with LDs estimated that up to a quarter of their students' population displayed challenging behavior, whilst just over $15 \%$ of schools estimated that up to a half of their students displayed challenging behavior. The main forms of challenging behavior have been identified as attention problems and hyperactivity, aggressive or destructive behavior, self-injurious behavior, stereotypy, and other socially or sexually unacceptable behaviors (Hastings \& Remington, 1994; Qureshi \& Alborz, 1992). Lack of comfort and ability in social situations may lead to frustration and disruptive behavior patterns in students with LDs. These behavior deficits are well documented (Hallahan, Kauffman, \& Pullen, 2009) and generally lead to the interruption or interference in the learning of other students in the classroom. Due to repeated academic failure and a focus on low academic achievement, many students with LDs develop a poor self-concept and low self-esteem. Likewise, repeated academic failure also leads to low levels of motivation in many students with LDs. It is difficult for these students to maintain intrinsic motivation when faced with academic circumstances that appear out of their control. However, the environments of the home, the school, the social group, and the culture influence a student's desire and ability to learn.

\subsection{The Teaching Environment}

Learning competencies depend on positive interactions with various environments. Realizing that learning, attitudes, and progress depend on positive interactions with the various environments, is an important feature of effective teaching. For example, home is the child's first environment. The child's experiences at home during the first five or six years influence cognitive development and lay the foundation for later school performance. As the child's first teacher, parents can provide intellectual stimulation and emotional well-being. The development of self-concept, self-esteem, interest in literacy, and a curiosity about learning all depend on the support and encouragement parents provide within the home. Similarly, a substantial portion of a student's day is spent in school, and school experience exerts dramatic effects. An integral part of the school experience is the student's relationship with peers and with school personnel (including teachers, aides, administrators, and office personnel). Unfortunately, many students with LDs not only encounter academic difficulty but often have problems acquiring appropriate school behaviors. They often have unsatisfactory relationships with teachers and classmates in the school environment, receive much less praise and acknowledgment for their efforts, and are more likely to be criticized, shown disapproval, and even ignored (Brooks, 2004).

Early identification and intervention for students with LDs and challenging behaviors will enhance the development of best practices in schools (Mather \& Goldstein, 2008). In view of this fact, it is of critical importance to have a practical assessment instrument to be used in identifying students who are at risk of LDs and challenging behaviors. When a child struggles in school, teachers must first determine the underlying factors contributing to the learning or behavior problem because when a child acts out, the reason may not be readily apparent. Similarly, when a child fails to or refuses to complete work, it is rarely because of poor motivation. Lowered motivation in students is often a secondary symptom resulting from chronic school difficulties. Goldstein and Mather (1998) have developed a framework for explaining why children experience learning and behavior problems in the classroom. This model is called the Building Blocks of Learning (BBL) (Mather \& Goldstein, 2008). In BBL model, the classroom behavior and learning problems of children were represented using a three level triangular framework reflecting foundational skills, symbolic or perceptual processing skills, 
and conceptual or thinking skills. Although learning does not consist of isolated skills, an understanding of the unique affective, behavioral, cognitive, and linguistic variables that influence development and school performance can help educators understand the various types of LDs and behavior disorders and subsequently design or select appropriate behavioral and academic interventions. The purpose of this multidimensional model is to represent many of the most common cognitive, motivational, environmental, and behavioral factors that may impede or enhance school performance. Fortunately, Mather and Goldstein (2008) have developed a practical assessment tool that called "Building Blocks Questionnaire" to represent the BBL model.

\subsection{The Context of the Study}

In 2012, the population of Jordan was estimated to be approximately 6,388,000 (Jordan Statistical Yearbook, 2012). The educational system in Jordan covers from Kindergarten to grade 12 including basic (primary and middle schools) and secondary schools. Basic schooling is free and compulsory for all Jordanian students. For the total student population in Jordan, $72 \%$ go to public schools and $28 \%$ go to private schools (Jordan Statistical Yearbook, 2012). In contrast to private schools, public schools are free of charge. In Jordan, the upper and upper middle class to a much greater extent send their children to private schools than families with lower income. In spite of educational reforms in the public school sector, private schools are still perceived better than public education. In Amman, the capital of Jordan, people has the highest income. Therefore, more people in Amman can afford private schooling for their children than people in other governorates.

In terms of the provided services for students with LDs and challenging behaviors, services for these students evolved in two distinct phases: relative isolation and integration. In the relative isolation phase, students were either denied access to public schools or permitted to attend in isolated settings. In the integration phase, which begun in the 1990s, students with LDs and challenging behaviors were mainstreamed, or integrated into general education programs. Considering that integration is a new practice, Jordan has recently made progress in teaching students with mild disabilities in public and private schools (Al-Khateeb \& Al-Khateeb, 2008). However, several researchers indicated that philosophies and practices of inclusion for students with LDs and challenging behaviors, as an advanced phase of integration, have not been clearly understood and implemented within the government, public, and private sectors (Abu-Hamour \& Al-Hmouz, 2013; Al-Khateeb \& Al-Khateeb, 2008). Furthermore, although gender research shows that actually there are as many girls with LDs as boys (Young, Kim, \& Gerber, 1999), the practitioners' observations in the special education field suggested that there are gender bias in the identification of students with LDs and challenging behaviors in Jordan. It seems that there are over-representation of boys when providing special education services.

\subsection{Significance of the Study}

The condition of LDs and challenging behaviors are universal problem that occurs in all languages, cultures, and nations in the world. Accumulating research shows that in all cultures there are children who seem to have normal intelligence but have severe difficulty in learning oral language, acquiring reading or writing skills, or doing mathematics. The problem appears in children learning an alphabet-based system of written language, such as Arabic (Abu-Hamour, 2013; Abu-Hamour \& Al-Hmouz, 2013; Abu-Hamour, Al-Hmouz, \& Kenana, 2013), and with children learning a logographic (pictorial) system of written language, such as Chinese (Hsu, 1998) or Japanese (Tsuge, 2001). However, very little current research has examined the characteristics of students with LDs and challenging behaviors when taking into the consideration their culture and school experiences.

As discussed previously, early identification of problems leads to greater odds of successful intervention efforts. Early identification refers to both identifying problems when children are young, as well as identifying early signs of problematic behaviors. Several researchers indicated that early signs of potential learning problems and behavioral disorders can be reliably detected (e.g., Dunlap et al., 2006; Feil et al., 2005). In addition, researchers had shown that the sooner LD is detected and intervention is begun, the better the chance to avoid school failure and to improve chances for success in life (Mather \& Goldstein, 2008). It is during the elementary school years that leaning problems frequently becomes apparent as disabilities interfere with increasingly demanding and complex learning tasks. When parents or teachers suspect a child has learning disabilities, they should seek evaluation.

Unfortunately, the trend in Jordan and other Arab countries has been (a) a reluctance to screen for early sign of problems in very young children, and (b) a tendency to accept minor misbehavior, even as it escalates, until the problem becomes severe and often unmanageable. Consistently, researchers in Jordan have stated in numerous reports and articles that the Jordanian educational system is in need of valid assessment tools to identify students with special needs and provide them with an appropriate intervention (Abu-Hamour, 2013; Abu-Hamour \& 
Al-Hmouz, 2013; Abu-Hamour \& Mattar, 2013). The Building Blocks Questionnaire (BBQ) that has been used in English speaking countries effectively, should be investigated for Arabic speaking countries. To the best of the author's knowledge, no studies had investigated the use of BBQ in Arabic language previously.

\subsection{Purposes of the Study}

This study aimed to explore the learning and behavioral characteristics of students with LDs in Jordan. A specific investigation for gender differences was performed as well. This study addressed following questions:

Study question 1: To what extent students with LDs are suffering from challenging behaviors?

Study question 2: To what extent do students with LDs in private schools differ from their counterparts in public schools?

Study question 3: To what extent do the Jordanian schools over-represent male students with LDs when providing special education services?

Study question 4: To what extent do male students differ from female students in terms of their performance on the Arabic BBQ?

\section{Method}

\subsection{Participants}

A total of 168 students with LDs (116 boys, 52 girls) were rated by four resource-room teachers ( 2 females and 2 males) on the BBQ. Each one of the teachers has a degree in early childhood education and a diploma in learning disabilities. These students were enrolled in two public schools and two private schools that located in Amman in the central region of Jordan. The schools were selected based on the school type, the location, and the large number of students who were enrolled in special education services. In these schools, resource-room teachers identified children in Grades 4, 5, and 6 who were classified as having LDs. All students who were so labeled had been evaluated prior to placement. Due to the lack of standardized assessment in Jordan, these teachers rely heavily on teacher-made tests of academic achievement, checklists, rating scales, and observations of LDs to make eligibility decisions. All participants spoke Arabic as a native language, and were not identified as having any exceptionality except for learning disabilities and behavioral problems. All participants were integrated in regular classrooms. Students were withdrawn for remediation for up to five hours per week by the resource room teachers. These students were enrolled in the second semester of 2012/2013. In the selected schools, curricular goals and objectives, materials, and instruction methods were similar. All classes were taught in Arabic. The schools followed the standard Jordanian national curriculum. Most of the participants in the private schools were from middle to upper socioeconomic status and most of the participants in the public schools were from a low socioeconomic status. Thirty one percent of the students were in fourth grade, $34 \%$ in fifth grade, and $35 \%$ were in sixth grade. The average age of the participants was 10.63 with a standard deviation of 1.36 . The sample's characteristics with regard to gender, grade, and age according to school's type are presented in Table 1.

Table 1. Demographic characteristics of the sample by schools

\begin{tabular}{lccc}
\hline \multicolumn{1}{c}{ Variable } & Public Schools & Private Schools & $\begin{array}{c}\text { Public and Private } \\
\text { Schools }\end{array}$ \\
\hline $\begin{array}{l}\text { Gender } \\
\text { Boys }\end{array}$ & 58 & 56 & 114 \\
Girls & 25 & 29 & 54 \\
\hline Grade & & & 52 \\
4 & 25 & 27 & 57 \\
5 & 29 & 28 & 59 \\
$\quad 29$ & 30 & 10.63 \\
\hline Age & 10.69 & 10.57 & 1.36 \\
M & 1.01 & 1.06 & \\
SD & &
\end{tabular}




\subsection{Procedures}

A letter from the author's university was sent to the Directorate of Special Education in Ministry of Education that supplemented by the questionnaire and the study purpose to request an ethical approval for the study. When approved, the Higher Council for the Affairs of Persons with Disabilities in Jordan provided the researcher with all descriptive information for schools that provided special education services for students with LDs in Amman. Schools were approached and permission was sought from the schools' principals. The researcher explained the purpose of the study for the resource room teachers and asked them to be part of the study. The resource room teachers were assured that the study was for scientific purposes only and that their responses were confidential and anonymous. The teachers were given four hours training workshop on how to complete the BBQ. The actual completion of the BBQ was rapid and took just a few minutes per student. The teachers completed the hard copy of the questionnaire and handed it back to the researcher within two weeks of giving them the questionnaire.

\subsection{Instrument}

The Building Blocks Questionnaire (BBQ) (Mather \& Goldstein, 2008) was adapted with permission from English language to Arabic language for the purpose of this study. The BBQ is designed to help educators to identify a student's strengths and weaknesses and to provide an overview of school-related skills and behaviors. In other words, the purpose of completing the questionnaire is to gain a better understanding of the factors that contribute to a student's successes and struggles in school. This questionnaire has two sections: Part 1 provides 10 questions, one question for each of the 10 building blocks, which are intended to provide a general overview of a student's strengths and weaknesses. The responses for these questions were: Rarely, Sometimes, or Frequently. Once the teachers have completed part 1, for each of the questions that they have answered frequently or sometime, they would proceed to part 2 of the questionnaire and complete the additional 10 items corresponding to that Building Block (BB). Part 2 provides an additional 10 items for each block in order to provide more in-depth information about the specifics of the behavior.

The 10 BB are: attention and self-regulation (e.g., "Does the student appear inattentive or impulsive?"); emotions (e.g., "Does the student appear to be sad?"); behavior (e.g., "Does the student have trouble following school rules?"); self-esteem (e.g., "Does the student appear to have a low opinion of him- or herself?"); phonological processing (e.g., "Does the student have difficulty hearing or applying letter sounds when speaking, reading, or spelling?"); orthographical processing (e.g.," Does the student have trouble reading or spelling words with irregular elements?"); motor processing (e.g., "Does the student have difficulty forming letters or writing legibly?"); thinking with language (e.g., "Does the student have trouble using or understanding oral language?"); thinking with images (e.g., "Does the student have difficulty creating mental pictures?"); and thinking with strategies (e.g., "Does the student have trouble forming or following a plan?"). A more detailed description of the BB items are given in Mather and Goldstein (2008).

The researcher used appropriate translation procedures (Brislin, 1986) to facilitate the use of BBQ in Arabic language. First, two native speakers of Arabic, who were also fluent in English, independently translated the BBQ into Arabic. Second, a back translation of the Arabic version into English was conducted by an English teacher who is fluent in both English and Arabic languages. Third, all translators reached an agreement on the forward-backward translations. Fourth, the BBQ was reviewed by five experts in the field of LDs who made comments on clarity and content that were incorporated in the final version of the instrument. Finally, a small-scale pilot study was conducted prior to the main study and only minor amendments to wording were required. For the present study, the internal consistency of the Arabic BBQ (obtained using Cronbach's alpha) was .91. In terms of social validity, teachers reported that the instructions for the BBQ were easy to understand and that they did not find completing the questionnaire difficult.

\subsection{Analyses}

The Statistical Package for the Social Sciences (SPSS), version 17.0, was used to analyze the data. Responses were analyzed using descriptive statistics, visual figures, and independent t-tests. The responses on the BBQ were in Likert-type form designated as follows: 1-"Rarely"; 2-"Sometimes"; 3-"Frequently". In terms of data entry reliability, all of the SPSS data (100\%) were checked against the paper scores and all discrepancies were resolved by examining the original protocols.

\section{Results}

An exploratory descriptive analysis was initially conducted. Table 2 contains a summary of the responses frequencies and percentages for each of the 10 components of the BBQ. Higher scores are indicative of more problematic behavior or learning aspects. Results were presented to address the school's type and the full sample. 
As expected, the distribution was skewed toward the highest scores because the sample of this study were diagnosed as students with LDs. With regard to the percentage of students with LDs who are suffering from challenging behaviors, between $52 \%$ and $60 \%$ of the total sample presented each of the four types of the behavioral aspects or components in the BBQ. On average, the results indicated that $51.9 \%$ of the students with LDs exhibited varying degrees (sometimes and frequently) of challenging behaviors.

\subsection{School's Type}

In public schools, between $68 \%$ and $80 \%$ of the total participants presented challenging behaviors. In addition, between $71 \%$ and $93 \%$ of the total participants presented learning problems. In private schools, between $35 \%$ and $48 \%$ of the total participants presented challenging behaviors. In addition, between $50 \%$ and $82 \%$ of the total participants presented learning problems (see Table 2). To compare the students in public and private schools in terms of their behavioral and learning problems, the responses of "sometimes" and "frequently" were collapsed into percentages and used to provide a visual presentation of their performance (see Figure 1). In general, the Figure indicates differences in all BBQ variables between the two types of schools and in favor of private schools.

\subsection{Gender Findings}

Of the total number of participants, $32 \%$ (54) were females and $68 \%$ (114) were males. These numbers suggested that there are an over representations of male students when providing special education services in Jordan. In terms of the gender differences, independent t-tests were conducted to examine the mean differences between males and females in the variables measured in this study (see Table 3). All assumptions of performing independent t-tests were examined. No violations of normality and homogeneity of variance were detected. The results indicated that female students perform better than male students in attention and self-regulation, behavior, and thinking with language. On the other hand, male students perform better than female students in emotions, self-esteem, and thinking with strategies. No significant differences between the two groups were detected for phonological processing, orthographical processing, motor processing, and thinking with images.

Table 2. Frequencies and percentages of responses for the 10 components of the building blocks questionnaire

\begin{tabular}{|c|c|c|c|c|c|c|c|c|c|}
\hline \multirow{2}{*}{$\begin{array}{l}\text { Building Block } \\
\text { Behavioral } \\
\text { Aspect }\end{array}$} & \multicolumn{3}{|c|}{ Public Schools } & \multicolumn{3}{|c|}{ Private Schools } & \multicolumn{3}{|c|}{ Public and Private Schools } \\
\hline & $\begin{array}{l}\begin{array}{l}\text { Rarel } \\
\mathrm{y} \quad \mathrm{N} \\
(\%)\end{array}\end{array}$ & $\begin{array}{l}\text { Sometimes } \\
\mathrm{N}(\%)\end{array}$ & $\begin{array}{l}\text { Frequently } \\
\mathrm{N}(\%)\end{array}$ & $\begin{array}{l}\text { Rarel } \\
\mathrm{y} \quad \mathrm{N} \\
(\%)\end{array}$ & $\begin{array}{l}\text { Sometim } \\
\text { es N (\%) }\end{array}$ & $\begin{array}{l}\text { Frequentl } \\
\text { y N }(\%)\end{array}$ & $\begin{array}{l}\text { Rarel } \\
\begin{array}{l}\text { y } \\
(\%)\end{array}\end{array}$ & $\begin{array}{l}\text { Sometimes } \\
\mathrm{N}(\%)\end{array}$ & $\begin{array}{l}\text { Frequently } \\
\mathrm{N}(\%)\end{array}$ \\
\hline $\begin{array}{l}\text { Attention and } \\
\text { Self-Regulation }\end{array}$ & $\begin{array}{l}26 \\
(31.3)\end{array}$ & $\begin{array}{l}16 \\
(19.3)\end{array}$ & $\begin{array}{l}41 \\
(49.4)\end{array}$ & $\begin{array}{l}44 \\
(51.8)\end{array}$ & $\begin{array}{l}21 \\
(24.7)\end{array}$ & $\begin{array}{l}20 \\
(23.5)\end{array}$ & $\begin{array}{l}70 \\
(41.7)\end{array}$ & $\begin{array}{l}37 \\
(22.0)\end{array}$ & $\begin{array}{l}61 \\
(36.3)\end{array}$ \\
\hline Emotions & $\begin{array}{l}24 \\
(28.9)\end{array}$ & $\begin{array}{l}20 \\
(24.1)\end{array}$ & $\begin{array}{l}39 \\
(47.0)\end{array}$ & $\begin{array}{l}52 \\
(61.2)\end{array}$ & $\begin{array}{l}15 \\
(17.6)\end{array}$ & $\begin{array}{l}18 \\
(21.2)\end{array}$ & $\begin{array}{l}76 \\
(45.2)\end{array}$ & $\begin{array}{l}35 \\
(20.8)\end{array}$ & $\begin{array}{l}57 \\
(33.9)\end{array}$ \\
\hline Behavior & $\begin{array}{l}16 \\
(19.3)\end{array}$ & $\begin{array}{l}17 \\
(20.5)\end{array}$ & $\begin{array}{l}50 \\
(60.2)\end{array}$ & $\begin{array}{l}51 \\
(60.0)\end{array}$ & $\begin{array}{l}13 \\
(15.3)\end{array}$ & $\begin{array}{l}21 \\
(24.7)\end{array}$ & $\begin{array}{l}67 \\
(39.9)\end{array}$ & $\begin{array}{l}30 \\
(17.9)\end{array}$ & $\begin{array}{l}71 \\
(42.3)\end{array}$ \\
\hline Self-Esteem & $\begin{array}{l}25 \\
(30.1)\end{array}$ & $\begin{array}{l}23 \\
(27.7)\end{array}$ & $\begin{array}{l}35 \\
(42.2)\end{array}$ & $\begin{array}{l}55 \\
(64.7)\end{array}$ & $\begin{array}{l}14 \\
(16.5)\end{array}$ & $\begin{array}{l}16 \\
(18.8)\end{array}$ & $\begin{array}{l}80 \\
(47.6)\end{array}$ & $\begin{array}{l}37 \\
(22.0)\end{array}$ & $\begin{array}{l}51 \\
(30.4)\end{array}$ \\
\hline Learning Aspect & & & & & & & & & \\
\hline $\begin{array}{l}\text { Phonological } \\
\text { Processing }\end{array}$ & $\begin{array}{l}11 \\
(13.3)\end{array}$ & $\begin{array}{l}11 \\
(13.3)\end{array}$ & $\begin{array}{l}61 \\
(73.5)\end{array}$ & $\begin{array}{l}34 \\
(40.0)\end{array}$ & $\begin{array}{l}11 \\
(12.9)\end{array}$ & $\begin{array}{l}40 \\
(47.1)\end{array}$ & $\begin{array}{l}45 \\
(26.8)\end{array}$ & $\begin{array}{l}22 \\
(13.1)\end{array}$ & $\begin{array}{l}101 \\
(60.1)\end{array}$ \\
\hline $\begin{array}{l}\text { Orthographical } \\
\text { Processing }\end{array}$ & $\begin{array}{l}5 \\
(6.0)\end{array}$ & $\begin{array}{l}19 \\
(22.9)\end{array}$ & $\begin{array}{l}59 \\
(71.1)\end{array}$ & $\begin{array}{l}18 \\
(21.2)\end{array}$ & $\begin{array}{l}24 \\
(28.2)\end{array}$ & $\begin{array}{l}43 \\
(50.6)\end{array}$ & $\begin{array}{l}23 \\
(13.7)\end{array}$ & $\begin{array}{l}43 \\
(25.6)\end{array}$ & $\begin{array}{l}102 \\
(60.7)\end{array}$ \\
\hline $\begin{array}{l}\text { Motor } \\
\text { Processing }\end{array}$ & $\begin{array}{l}21 \\
(25.3)\end{array}$ & $\begin{array}{l}29 \\
(34.9)\end{array}$ & $\begin{array}{l}33 \\
(39.8)\end{array}$ & $\begin{array}{l}42 \\
(49.4)\end{array}$ & $\begin{array}{l}20 \\
(23.5)\end{array}$ & $\begin{array}{l}23 \\
(27.1)\end{array}$ & $\begin{array}{l}63 \\
(37.5)\end{array}$ & $\begin{array}{l}49 \\
(29.2)\end{array}$ & $\begin{array}{l}56 \\
(33.3)\end{array}$ \\
\hline
\end{tabular}




\begin{tabular}{lllllllllll}
\hline Thinking & with & 24 & 21 & 38 & 36 & 24 & 25 & 60 & 45 & 63 \\
Language & & $(28.9)$ & $(25.3)$ & $(45.8)$ & $(42.4)$ & $(28.2)$ & $(29.4)$ & $(35.7)$ & $(26.8)$ & $(37.5)$ \\
Thinking & with & 11 & 16 & 56 & 15 & 25 & 45 & 26 & 41 & 101 \\
Images & & $(13.3)$ & $(19.3)$ & $(67.5)$ & $(17.6)$ & $(29.4)$ & $(52.9)$ & $(15.5)$ & $(24.4)$ & $(60.1)$ \\
Thinking & \multirow{2}{*}{ with } & 19 & 15 & 49 & 21 & 17 & 47 & 40 & 32 & 96 \\
Strategies & & $(22.9)$ & $(18.1)$ & $(59.0)$ & $(24.7)$ & $(20.0)$ & $(55.3)$ & $(23.8)$ & $(19.0)$ & $(57.1)$ \\
\hline
\end{tabular}

Note: $\mathrm{n}=83$ for public schools, $\mathrm{n}=85$ for private schools, $\mathrm{N}=168$ for public and private schools.

Table 3. Differences between females and males in building block questionnaire variables

\begin{tabular}{|c|c|c|c|c|c|}
\hline Building Block & Gender & $\mathrm{M}$ & SD & $P$ & $r$ \\
\hline \multicolumn{6}{|l|}{ Behavioral Aspect } \\
\hline \multirow[t]{2}{*}{ 1. Attention and Self-Regulation } & Male & 2.58 & .81 & .006 & .21 \\
\hline & Female & 2.19 & .93 & & \\
\hline \multirow[t]{2}{*}{ 2. Emotions } & Male & 1.62 & .85 & .000 & .43 \\
\hline & Female & 2.46 & .71 & & \\
\hline \multirow[t]{2}{*}{ 3. Behavior } & Male & 2.40 & .84 & .000 & .35 \\
\hline & Female & 1.72 & .81 & & \\
\hline \multirow[t]{2}{*}{ 4. Self-Esteem } & Male & 1.79 & .84 & .000 & .37 \\
\hline & Female & 2.48 & .72 & & \\
\hline \multicolumn{6}{|l|}{ Learning Aspect } \\
\hline \multirow[t]{2}{*}{ 5. Phonological Processing } & Male & 2.48 & .76 & .664 & .03 \\
\hline & Female & 2.54 & .74 & & \\
\hline \multirow[t]{2}{*}{ 6.Orthographical Processing } & Male & 2.23 & .79 & .457 & .05 \\
\hline & Female & 2.13 & .80 & & \\
\hline \multirow[t]{2}{*}{ 7. Motor Processing } & Male & 2.28 & .82 & .907 & .00 \\
\hline & Female & 2.30 & .76 & & \\
\hline \multirow[t]{2}{*}{ 8. Thinking with Language } & Male & 2.08 & .90 & .011 & .19 \\
\hline & Female & 1.70 & .83 & & \\
\hline \multirow[t]{2}{*}{ 9. Thinking with Images } & Male & 2.37 & .75 & .537 & .04 \\
\hline & Female & 2.44 & .71 & & \\
\hline \multirow[t]{2}{*}{ 10. Thinking with Strategies } & Male & 1.96 & .91 & .000 & .32 \\
\hline & Female & 2.57 & .69 & & \\
\hline
\end{tabular}

Note: $\mathrm{n}=54$ for female students, $\mathrm{n}=114$ for male students, $\mathrm{M}=$ Mean, $\mathrm{SD}=$ Standard Deviation, $\mathrm{p}=$ Significance, Level, $r=$ Effect Size. 


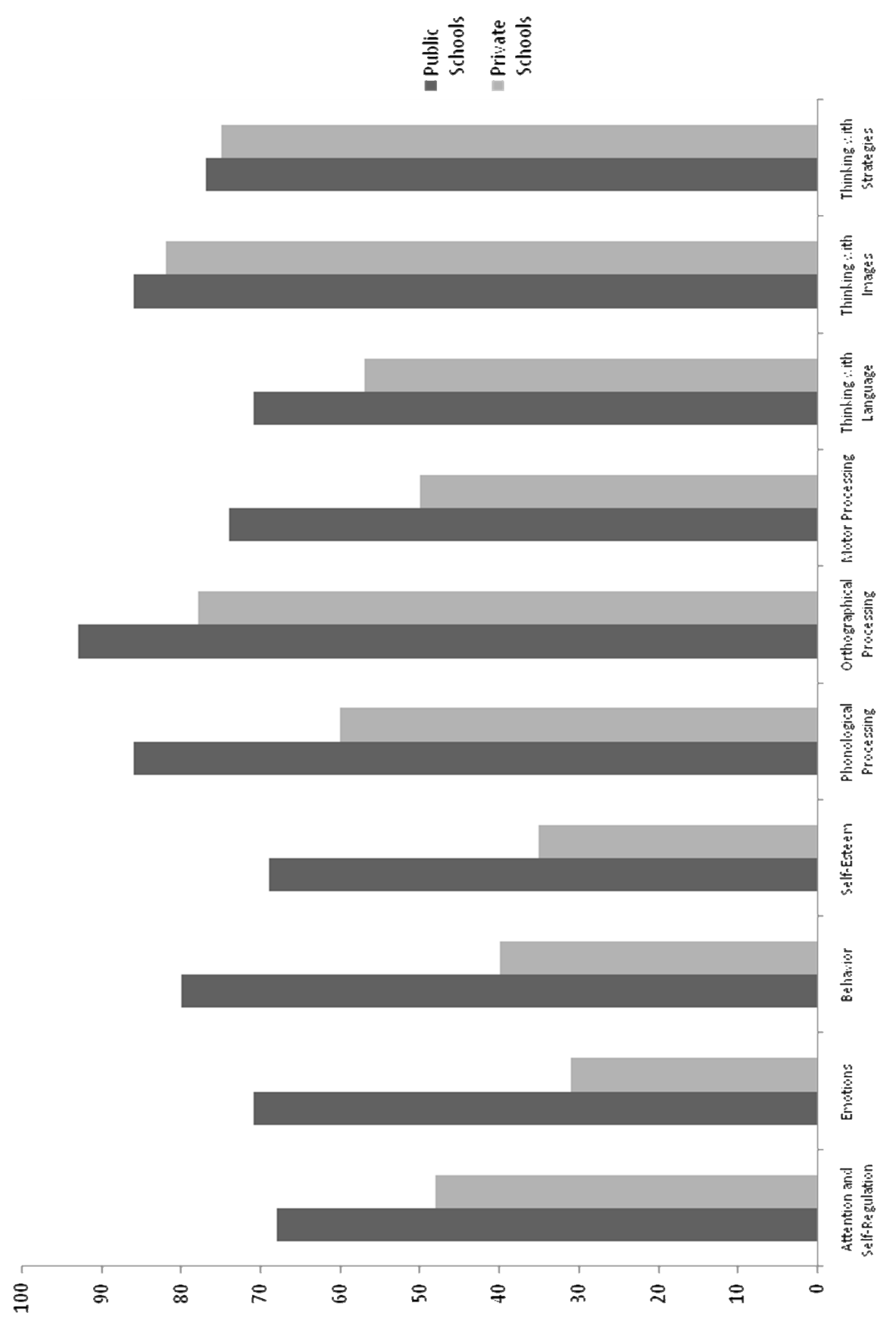

Figure 1. Percentages of behavioral and learning problems among students with learning disabilities in public and private schools 


\section{Discussion}

This study aimed to explore the conditions of students with LDs in Jordan. Specifically, variables that related to challenging behaviors, school's type, and gender differences were investigated. The findings of this study indicate that over half of the students with LDs are suffering from challenging behaviors. The high rates of comorbidity between LDs and challenging behaviors are well-documented in research (Bender \& Smith, 1990; Forness \& Kavale, 2001; Hallahan, Kauffman, \& Pullen, 2009; Mather \& Goldstein, 2008). For example, Bender and Smith (1990) found that teachers' ratings and classrooms observations revealed excessive off-task behavior, conduct disorders, and other behavioral problems for children with LDs. They concluded that students with LDs may not understand how to do their schoolwork and become frustrated and act out as a result.

One important finding of this study is that students with LDs in private schools presented a better learning and behavioral profile than students with LDs in public schools. As indicated previously, in Jordan, the upper and upper middle class send their children to private schools than families with lower income. In families with higher income, parents tend to have higher education than poorer parents, and they are thus in a much better position to help and support their children through school. In other words, the public schools that located in low-socioeconomic status communities are often under resourced and this negatively affecting students' academic progress. In addition, children from low-socioeconomic status environments acquire language skills more slowly, exhibit delayed letter recognition and phonological awareness, and are at risk for LDs (Aikens \& Barbarin, 2008). Increasing evidence supports the link between lower socioeconomic status and LDs. Children from lower socioeconomic status households are about twice as likely as those from high-socioeconomic status households to display learning-related behavior problems (Arnold \& Doctoroff, 2003).

Although gender research shows that there are as many girls with LDs as boys (Young et al., 1999), the results of this study suggested that there are gender bias in the identification of students with LDs in Jordan. This study reported that about two-thirds of all students with LDs were boys. This leads to the conclusion that there is an under identification of girls with LDs. This finding is consistent with a study in England reported that boys were 2.5 times more likely than girls to be identified with special education needs (Strand \& Lindsay, 2009). Girls with LDs who are not identified are an underserved group that is at significant risk for long-term academic, social, and emotional difficulties. Explanations of why more boys than girls are identified with LDs include cultural factors (more males may be identified because boys tend to exhibit more disruptive behaviors that are troublesome to adults), and expectation pressures (the expectations for success in school may be greater for boys than for girls).

With regard to the gender differences, educators have long been aware of the educational achievement differences between boys and girls. Historically, girls have displayed stronger reading abilities in the elementary school years, and boys outperform girls in math and science in the middle school and high school years (Ma, 2008). However, inconsistent and evolving evidence on cognitive differences between boys and girls in the general population establishes an uneasy foundation for examining gender differences among students with disabilities in special education field. For example, boys with LDs tend to exhibit more physical aggression and loss of control, visual-motor disability, spelling disability, and problems in written language mechanical aptitude; while girls with LDs tend to have more cognitive deficits in reading and math (Vogel, 1990). The results of this study lend more support to the gender differences research and indicate that girls with LDs perform better than boys in attention and self-regulation, behavior, and thinking with language; while boys with LDs perform better than girls in emotions, self-esteem, and thinking with strategies. These differences should be considered to provide an appropriate intervention that fits the unique need of each student.

\subsection{Implications, Future Research, and Limitations}

In this study, the researcher attempted to offer an effective tool that may serve as a quick and valid screening procedure to identify students with LDs and challenging behaviors. As indicated previously, the Jordanian and other Arabic educational systems are in need of valid assessment tools to identify students with special needs and provide them with an appropriate intervention. The BBQ proposed here should fill this gap and help teachers to identify students who might need further help to success in schools. Future research that will investigate the BBQ across different ages or grades is warranted.

It is very critical for teachers to consider the fact that most of the students with LDs are suffering from challenging behaviors and disadvantaged environment. By understanding the powerful role of environmental factors in the classroom, teachers can enhance each child's educational success and also create an effective setting for learning. Strengthening a student's sense of self-esteem and emotional well-being is not an extra curriculum; if anything, a student's sense of belonging, security, and self-confidence provide the scaffolding that 
supports the foundation for enhanced learning, motivation, and self-discipline. Teachers must provide social and emotional interventions hand in hand with academic education (Merrel, 2002). In fact, a sustainable school environment must be capable of meeting the social, emotional, and academic needs for all students (Goldstein \& Brooks, 2007).

Although the results of the present work have clear implications for the students with LDs and challenging behaviors, several limitations to the present study should be acknowledged. First, the participants of this study are students with LDs, without sub-grouping by types of learning disabilities (e.g., dyslexia, dyscalculia, dysgraphia) which may affect the results. Future research may explore how different kinds of LDs impact different groups and settings. Second, the present study used resource room teachers' ratings on BBQ, believing this to provide an accurate and unbiased assessment of students with LDs and challenging behaviors. Future research may include both a teacher and a parent rating for comparison purposes and to further examine the relationship between parent and teacher perceptions. Finally, researchers and policy makers should investigate the factors that establish gender equity in education and support teaching and learning for both boys and girls.

\section{References}

Abu-Hamour, B. (2013). Arabic spelling and curriculum based measurement. The Australian Educational and Developmental Psychologist Journal, 30, 140-156. http://dx.doi.org/10.1017/edp.2013.10

Abu-Hamour, B., \& Al-Hmouz, H. (2013). Special Education in Jordan. European Journal of Special Needs Education, 29(1), 105-115. http://dx.doi.org/10.1080/08856257.2013.859820

Abu-Hamour, B., \& Mattar, J. (2013). The applicability of curriculum-based-measurement in math computation in Jordan. International Journal of Special Education, 28(1), 111-119.

Abu-Hamour, B., Al Hmouz, H., \& Kenana, M. (2013). The effect of short vowelization on CBM reading fluency and comprehension in Arabic. Australian Journal of Learning Difficulties, 18(2), 181-197. http://dx.doi.org/10.1080/19404158.2013.852980

Aikens, N. L., \& Barbarin, O. (2008). Socioeconomic differences in reading trajectories: The contribution of family, neighborhood, and school contexts. Journal of Educational Psychology, 100(2), 235-251. http://dx.doi.org/10.1037/0022-0663.100.2.235

Al-Khateeb, J., \& Al-Khateeb, F. (2008). Educating students with mild intellectual disabilities in Jordan. Journal of the International Association of Special Education, 8(1), 109-116.

Arnold, D. H., \& Doctoroff, G. L. (2003). The early education of socioeconomically disadvantaged children. Annual Review of Psychology, 54, 517-545. http://dx.doi.org/10.1146/annurev.psych.54.111301.145442

Bender, W. N., \& Smith, J. K. (1990). Classroom behavior of children and adolescents with learning disabilities. Journal of Learning Disabilities, 23, 298-306. http://dx.doi.org/10.1146/annurev.psych.54.111301.145442

Berninger, V. (2009). Assessing and intervening with children with written language disorders. In D. Miller (Ed.), Best practices in school neuropsychology (pp. 507-520). New York: Wiley.

Brooks, R. B. (2004). To touch the hearts and minds of students with learning disabilities: The power of mindsets and expectations. Learning Disabilities: A contemporary Journal, 2, 9-18.

Chamberlain, L., Cheung-Chung, M., \& Jenner, L. (1993). Preliminary findings on communication and challenging behavior in learning disabilities. $B r \quad J$ Dev Disabilities, 31, 118-125. http://dx.doi.org/10.1179/bjdd.1993.014

Denton, C. A., Vaughn, S., \& Fletcher, J. M. (2003). Bringing research based practice in reading intervention to scale. Learning Disabilities Research \& Practice, 18, 201-211. http://dx.doi.org/10.1111/1540-5826.00075

Dunlap, G., Strain, P. S., Fox, L., Carta, J. J., Conroy, M., Smith, B. J., . . Sowell, C. (2006). Prevention and intervention with young children's challenging behavior: Perspectives regarding current knowledge. Behavioral Disorders, 32, 29-45.

Ehri, L., \& McCormick, S. (1998). Phases of word learning: Implications for instruction with delayed and disabled readers. Reading and Writing Quarterly, 14, 135-163. http://dx.doi.org/10.1080/1057356980140202

Feil, E. G., Small, J. W., Forness, S. R., Serna, L. A., Kaiser, A. P., Hancock, T. B., . . Lopez, M. L. (2005). Using different measures, informants, and clinical cut-off points to estimate prevalence of emotional or behavioral disorders in preschoolers: Effects on age, gender, and ethnicity. Behavioral Disorders, 30, 375-391. 
Forness, S., \& Kavale, K. (2001). ADHD and a return to the medical model of special education. Education \& Treatment of Children, 24, 224-247.

Gersten, R., Fuchs, L. S., Williams, J. P., \& Baker, S. (2001). Teaching reading comprehension strategies to students with learning disabilities: A review of the research. Review of Educational Research, 71, 279-320. http://dx.doi.org/10.3102/00346543071002279

Goldstein, S., \& Brooks, R. (2007). Understanding and managing children's classroom behavior: Creating sustainable, resilient schools (2nd ed.). New York: Wiley.

Goldstein, S., \& Mather, N. (1998). Overcoming underachieving: An action guide to helping your child succeed in school. New York: Wiley.

Hallahan, D. P., Kauffman, J. M., \& Pullen, P. C. (2009). Exceptional learners: An introduction to special education (11th ed.). Boston: Allyn \& Bacon.

Hastings, R. P., \& Remington, B. (1994). Rules of engagement: Towards an analysis of staff responses to challenging behavior. Research in Developmental Disabilities, 15, 279-298. http://dx.doi.org/10.1016/0891-4222(94)90008-6

Hsu, C. (1998). Correlate of reading success and failure in a logographic writing system. Thalmus, 6, 33-59.

Jordan Statistical Yearbook. (2012). Department of Statistics, 63. Amman, Jordan.

Ma, X. (2008). Within-school gender gaps in reading, mathematics, and science literacy. Comparative Education Review, 52, 437-460. http://dx.doi.org/10.1086/588762

Male, D. B. (1996). "Who goes to SLD schools?” Journal of Applied Research in Intellectual Disabilities, 4(4), 307-325. http://dx.doi.org/10.1111/j.1468-3148.1996.tb00117.x

Merrell, K. W. (2002). Social-emotional intervention in schools: Current status, progress, and promise. School Psychology Review, 31, 143-147.

National Research Center on Learning Disabilities. (2007). SLD identification overview: General information and tools to get started [Brochure]. Lawrence, KS: Author.

Qureshi, H., \& Alborz, A. (1992). The epidemiology of challenging behavior. Mental Handicap Research, 5, 130-145. http://dx.doi.org/10.1111/j.1468-3148.1992.tb00041.x

Shaley, R. S., Manor, O., \& Gross-Tsur, V. (2005). Developmental dyscalculia: A prospective six-year follow-up. Developmental Medicine \& Child Neurology, 47, 121-125. http://dx.doi.org/10.1017/S0012162205000216

Smith, C. R. (1994). Learning disabilities: The interaction of learner, tasks, and setting (3rd ed.). Boston: Allyn \& Bacon.

Strand, S., \& Lindsay, G. (2009). Ethnic disporoportionality in special education. The Journal of Special Education, 43(3), 117-126.

Swanson, H. L. (2009). Working memory, short-term memory, and reading disabilities: A selective meta-analysis of the literature. Journal of Learning Disabilities, 42, 260-287. http://dx.doi.org/10.1177/0022219409331958

Tsuge, M. (2001). Learning disabilities in Japan. In D. Mallahan, \& B. Keogh (Eds.), Research and global perspectives in learning disabilities: Essays in honor of William M. Cruickshank (pp. 255-272). Mahwah, NJ: Erlbaum.

United States Department of Education. (USDOE). (2004). IDEA, Individuals with Disabilities Education Improvement Act of 2004. Public Law 108-446, 108th Cong., 118 Stat. 2647.

Vogel, S. A. (1990). Gender differences in intelligence, language, visual-motor abilities, and academic achievement in students with learning disabilities: A review of the literature. Journal of Learning Disabilities, 23, 44-52. http://dx.doi.org/10.1177/002221949002300111

Young, G. H., Kim, H. J., \& Gerber, P. J. (1999). Gender bias and learning disabilities: School age and long term consequences for females. Learning Disabilities Journal, 3, 107-114. 


\section{Copyrights}

Copyright for this article is retained by the author(s), with first publication rights granted to the journal.

This is an open-access article distributed under the terms and conditions of the Creative Commons Attribution license (http://creativecommons.org/licenses/by/3.0/). 